\title{
Representações sociais de futuros docentes sobre a Teoria da Evolução darwinista
}

\author{
Social representations of the future educators concerning the \\ Darwin's Theory of Evolution
}

Fernanda Cândido MAGALHÃES'

\begin{abstract}
Resumo
A Teoria da Evolução de Darwin, que apresenta ampla repercussão no senso comum, é o objeto desse estudo do campo representacional. Para interpretação dos dados utilizou-se a Teoria das Representações Sociais. O método de coleta consistiu no levantamento da estrutura das representaçóes sobre a Teoria da Evolução, entre 179 estudantes dos cursos de Pedagogia e Biologia. O estudo apontou forte ligação entre a Teoria da Evolução e a imagem de Darwin. Mesmo com o passar de 150 anos, teoria e autor estão presentes no conhecimento popular, rompendo as barreiras do universo científico para circular amplamente nas representaçôes desses futuros professores.
\end{abstract}

Palavras-chave: Educadores em Formação. Teoria da Evolução. Representaçôes Sociais.
Abstract

Darwin's theory of evolution, which has wide repercussions in common sense, is the object of this study of the representational field. The study counted on the Theory of Social Representations to interpret the data. The method of data gathering consisted of the investigation on the structure of the representations about the Theory of Evolution among 179 students enrolled in the courses of Pedagogy and Biology. The study indicated a strong connection between the Theory of Evolution and the image of Darwin. Even over a long period of 150 years, the theory and author are present in the popular knowledge, breaking the barriers of the scientific universe to circulate widely throughout the representations of these future teachers.

Keywords: Educators' Formation. Theory of Evolution. Social Representations.

1 Doutora em Psicologia Social, pela Universidade do Estado do Rio de Janeiro. Docente do Departamento de Psicologia da Universidade Federal de Mato Grosso (UFMT). Coordenadora da Pós-Graduação em Psicologia da UFMT. Endereço institucional: Av. Fernando Corrêa da Costa, 2367, Cuiabá/MT. CEP: 78060-910. Telefone: (65) 3615-8436. E-mail: <fernanda.candido2010@gmail.com>.

R. Educ. Públ.

\section{Cuiabá}

v. 27

n. 66 p. $839-857$ set./dez. 2018 
A Teoria da Evolução, conforme proposta por Charles Darwin há mais de 150 anos, circula no meio científico de modo a gerar muitas polêmicas na academia e a apresentar, também, ampla repercussão nos conhecimentos de senso comum. Essa teoria modificou notoriamente o pensamento do universo reificado e também do consensual, em especial por contradizer a teoria criacionista acerca do surgimento da humanidade. Assim, pretende-se saber o estado em que se encontram hoje as representaçóes construídas sobre tal teoria, no âmbito de um estrato cultural bem-informado e que futuramente terá o compromisso profissional de repassar essas informaçôes, os estudantes de licenciatura.

Deu-se preferência à investigação com objeto proveniente do conhecimento científico, em consonância com o que asseveram Clémence, Green e Courvoisier (2011, p. 180):

[...] o desenvolvimento da ciência, sua crescente importância na educação e difusão na sociedade contribuem para alimentar continuamente o senso comum com os novos objetos de representação, enquanto as fontes do pensamento profano, como as religióes ou as mitologias, sufocam-se. É bastante surpreendente que a maioria dos estudos sobre as representaçôes não se situa nesta perspectiva.

Nesse sentido, em formato aproximado ao de Moscovici (1978), em seu estudo que deu origem à Teoria das Representaçôes Sociais, buscou-se conhecer o atravessamento de um conhecimento do universo reificado para o universo consensual, no caso a Teoria da Evolução darwinista apropriada pelo senso comum, tendo em vista que são conhecimentos a carregarem valores, crenças e atitudes que servirão de guia para a prática da docência.

Os resultados aqui apresentados consistem na descrição empírica das representaçôes sociais acerca da Teoria da Evolução, construídas, mantidas e atualizadas no âmbito de uma amostra populacional brasileira. Em consonância com sua fundamentação psicossocial, este estudo não tem a finalidade precípua de identificar acordos e desacordos entre as representaçóes sociais e a própria Teoria da Evolução, mas sim de conhecer o conteúdo e a estrutura desses conhecimentos cotidianos.

Como hipótese de investigação acreditava-se que as representaçóes poderiam se caracterizar pela combinação de diferentes concepçóes - darwinista, lamarckista, criacionista, etc., entendendo-se isso como possível estratégia sociocognitiva para lidar com questóes tão divergentes.

Importante salientar que atualmente a busca pelo espaço escolar tem sido pleiteada por criacionistas que contradizem os argumentos empregados em 
prol da evolução e reivindicam posição equivalente, no currículo escolar, para o ensino da história cristá sobre a origem das espécies. Nesse sentido, o contexto representacional de futuros docentes dáo conta de expressar os sentidos que atribuem à teoria evolucionista.

\section{A Teoria da Evolução darwinista}

Di Mare (2002) avalia que a Teoria da Evolução tenha sido a principal contribuição da Biologia para a história das ideias no século XIX, o que fez com que os cientistas abandonassem a imagem newtoniana do mundo, como uma máquina que foi totalmente construída pelas mãos de Deus, e a substituíssem pelo conceito de um sistema evolutivo em constante mudança.

Charles Lyell, autor de Princípios de geologia (1835), livro que Darwin estudou no decorrer de toda sua expedição, foi um dos primeiros a incentiválo a expor suas ideias de maneira completa, mas Darwin acreditava que sua produção ainda não estava preparada para publicação. Para Darwin (2000, p. 104, grifos do autor), seus escritos estavam "[...] numa escala três ou quatro vezes maior do que a que finalmente apareceu em $A$ origem das espécies; mesmo assim, tratava-se apenas de um resumo do material que havia colecionado, e cheguei a aproximadamente metade do trabalho nessa escala."

Com esse pensamento, Darwin segue por quase 20 anos sem publicar suas descobertas. Uma das razóes para essa demora teria sido o desejo de apoiar cada hipótese em fatos, intentando evitar o mesmo destino da teoria de seu predecessor Lamarck.

A teoria defende a ideia central, a seleção natural, na qual a espécie preserva características que favorecem sua sobrevivência, estabelecendose uma luta pela existência entre os organismos. A evolução não indica a existência de uma superioridade entre seres, ou mesmo a superioridade da espécie sobrevivente, mas demonstra a capacidade adaptativa dos seres. O que sucede é que, na luta pela sobrevivência, os organismos mais fracos tendem a morrer primeiro, já os mais saudáveis se adaptam e permanecem.

Para a explanação de sua teoria, Darwin visualizou a evolução da vida a partir de um diagrama, posteriormente denominado $A$ grande árvore da vida, com o qual evidenciava a natureza das afinidades muito complexas entre animais do passado e do presente. Essa figura, no entender de Browne (2007), veio para substituir a antiga imagem da árvore do conhecimento, a árvore da vida apresentada na Bíblia. Entretanto, sua árvore representa o tempo, a história, o conhecimento e a vida, mas de forma alguma proporciona aspectos da divindade. 
O darwinismo ganhou o mundo com muita rapidez, e sua chegada no Brasil não foi diferente, propiciando diversos debates com estudiosos que apresentavam posiçóes contrárias, e outros em defesa dessa teoria evolucionista. E, mesmo com o passar dos 150, evidencia-se a repercussão desse tema em estudos atuais, como apontam as pesquisas a seguir.

Pagan (2010), em investigação com graduandos de ciências biológicas da Universidade do Estado de Mato Grosso, apresentou como objetivo identificar influências e tendências evolutivas e criacionistas nas concepçóes sobre o ser humano, tendo como norteadoras três questôes existenciais: quem somos, de onde viemos e para onde vamos. Seu estudo evidenciou que as falas dos estudantes emergiram com bases tanto científicas quanto religiosas, sendo que as primeiras manifestaram-se nas ideias de proximidade filogenética entre os organismos vivos, já as segundas, que não negaram as primeiras, refletiram tentativas de síntese entre esses paradigmas. Algumas dessas sínteses implicaram em distorção sobre os fundamentos epistemológicos da ciência e da religiáo, transferindo-as ao nível das interpretaçóes individuais. Tanto religiáo quanto ciência estáo amarradas a forças que transcendem à razão e à fé e se ligam a anseios profissionais.

Por sua vez, a investigação realizada por Dorvillé (2010) analisou os conflitos e as tensóes vivenciados por licenciandos evangélicos da Faculdade de Formação de Professores da Universidade do Estado do Rio de Janeiro, no tocante às suas visôes de mundo e ao ensino de algum conteúdo biológico, especialmente o relacionado com a evolução dos seres vivos. Seus resultados, embasados na sociologia de Bourdieu, analisaram o potencial de promover alterações na visão de mundo desses alunos investigados, especialmente por meio da promoção de situaçóes dissonantes com o habitus original desses alunos. Defende, por igual, a garantia do caráter laico das escolas e universidades públicas, resguardando os alunos de reproduzir, em seu interior, espaços religiosos com os quais eles já se encontram familiarizados, seja na própria família, seja na comunidade religiosa de origem.

Depois de muitas polêmicas, discordâncias e controvérsias enfrentadas, a Teoria da Evoluçáo proposta por Darwin conquistou lugar de respeito na academia. Ao mesmo tempo em que está consolidada no universo científico, essa perspectiva teórica tem sido objeto da formação de representaçôes sociais, conhecimentos que nem sempre coincidem com as formulaçôes científicas e, em rigor, frequentemente delas se distanciam, quando não a elas se opóem frontalmente. 


\section{Teoria das Representações Sociais: o aporte teórico}

A psicologia social é descrita por Moscovici (2003, p. 129) como um movimento de pesquisa e de metodologia que agrega diferentes interesses para o enriquecimento desse movimento. No que diz respeito a essa diversidade no interior da psicologia, o autor assevera ser "[...] um campo cercado ao redor de um mosaico, nossa aparência de coesão é devida a pressão interna, mas nossa dependência de interesses, técnicas e ciências diversas continua a nos separar uns dos outros."

A teoria formulada por Moscovici assume como centro a comunicaçáo, pois essa é base para a constituiçáo das representaçóes, com a proposta de elucidar ligaçôes entre a psicologia e as questóes sociais e culturais. Com essa aproximação, as representaçóes ensejam que grupos se familiarizem com os novos conhecimentos.

O desenvolvimento histórico da psicologia social é fortemente marcado por uma vertente individualista; contudo, Serge Moscovici (1961/1976), ao formular a Teoria das Representaçóes Sociais (TRS), por meio da obra La Psychanalyse, son image et son public, contribuiu decisivamente para o reforço de uma forma sociológica de psicologia, que fora sempre minoritária nessa ciência.

Nesse aspecto, a proposta moscoviciana buscou, também na sociologia, uma fonte teórica para dar a devida ênfase ao social na psicologia. A Teoria das Representaçóes Sociais tem, como ancestral, Durkheim e seus estudos sobre as representaçóes coletivas. Moscovici (2003) faz referência igualmente a Piaget e Vygotsky, raízes para sua análise do social. Bem assim, um estudioso das representaçóes coletivas, a Levy-Brühl, que destacou o valor da relatividade cultural.

Importante demarcar a diferenciação entre os conhecimentos de senso comum e os científicos, provenientes do universo reificado, sendo esses últimos descritos por Moscovici (2003) como pertencentes a uma sociedade em que os papéis e as classes são diferenciados, à medida que as pessoas adquirem competências. Já o senso comum diz respeito aos conhecimentos que as pessoas náo precisam de competências específicas para se expressar.

Existem discussóes protagonizadas por diversos colaboradores que contribuíram para a construção da Teoria das Representaçôes Sociais, dentre os quais se destaca Jodelet $(2001$, p. 22), que assim define representação social:

[...] forma de conhecimento, socialmente elaborada e partilhada, com um objetivo prático, e que contribui para a construçáo de uma realidade comum a um conjunto social. Igualmente designada como um saber de senso comum ou 
ainda saber ingênuo, natural, esta forma de conhecimento é diferenciada, entre outras, do conhecimento científico.

Os conhecimentos provêm de indivíduos, mas são frutos de uma construção comum e de um compartilhamento entre pessoas, o que ocorre por meio das comunicaçóes. Esses conhecimentos, conforme argumenta a autora, têm a finalidade de tornar conhecida a realidade em que se vive.

Diante dos conceitos ora estampados, releva-se a forma pela qual os conhecimentos são construídos em grupo, pelas conversaçóes, e dizem respeito a algo vivenciado, que seja também significativo para os participantes. Essa prática, no entendimento de Moscovici (2003), faz com que as representaçóes atravessem a mente das pessoas, como se não fossem pensadas, mas, de certa forma, repensadas e pronunciadas. Com base na troca de informaçóes no grupo, atinge-se a finalidade das representaçóes sociais, qual seja a de tornar familiar algo que seja desconhecido. As conversaçóes sobre os conhecimentos estranhos possibilitam que esses passem a ser comuns.

Ao investigar representações sociais, é possível a utilização de abordagens complementares à teoria geral. Jean-Claude Abric, em 1976, formulou a Teoria do Núcleo Central, que se ocupa mais do conteúdo cognitivo das representaçóes. Denominada estrutural, o autor propõe que as representaçóes se organizam em um sistema central e em um sistema periférico, com características e funçóes distintas. Na sequência, será esboçada breve descrição dos conceitos e proposiçóes centrais dessa teoria, bem assim as mudanças ao longo do tempo.

\section{Abordagem estrutural das representações sociais}

Jean-Claude Abric, em 1976, propõe a Teoria do Núcleo Central (TNC), com objetivo de estudar a estrutura das representaçóes sociais. Assim, procurou compreender os conhecimentos do senso comum, divididos em dois sistemas, denominados central e periférico.

Uma característica que pode ser encontrada com o uso dessa abordagem é a objetividade das investigaçóes, o que enseja apreender detalhes existentes no conhecimento e no comportamento das pessoas. Segundo Sá (2002), tal ausência foi alvo de críticas a Moscovici, quando propôs a Teoria das Representaçóes Sociais. Assim, a escolha da abordagem representa um complemento à teoria geral, servindo como referencial de apoio.

Importante salientar que a referida teoria complementar encontra respaldo na própria Teoria das Representaçóes Sociais, com o conceito de núcleo figurativo, 
sendo esse "[...] uma estrutura imagética em que se articulam, de forma mais concreta ou visualizável, os elementos do objeto de representação que tenham sido selecionados pelos indivíduos ou grupos [...]” (SÁ, 2002, p. 65).

Núcleo Central (NC) é definido por Abric (2003) como conjunto de elementos da representaçáo que sobressaem como os mais estáveis e menos vulneráveis às mudanças nas situações de vida do grupo. Sáo elementos das representaçóes que se caracterizam por estar encadeados à memória coletiva e à história do grupo; sáo consensuais, portanto, definem a homogeneidade dos conhecimentos; traduzem a estabilidade, a coerência, a rigidez e a resistência à mudança da representação, logo, são pouco sensíveis ao contexto imediato; geram o significado da representação e determinam sua organização.

Por sua vez, o sistema periférico representa o mais acessível da representação. É composto pelos elementos periféricos e pela zona de contraste, e estão alojados em torno do núcleo central. Correspondem aos dados mais acessíveis e concretos da representação, cuja função é sustentar e proteger o núcleo. Entre as principais características dos elementos do sistema periférico destacam-se: permitem a integração de experiências e histórias individuais, assim, franqueiam a heterogeneidade; possuem flexibilidade e tolerância às contradiçóes; são evolutivos; são sensíveis ao contexto imediato; facultam a adaptação à realidade concreta e à diferença de conteúdo (ABRIC, 2003). Nessa marcha, pode-se dizer que a transformação da representação tem seu início com as mudanças nos elementos do sistema periférico, pois são eles que comportam contradiçóes, suscetíveis às possíveis alteraçôes.

\section{Procedimentos metodológicos}

Para seleção dos participantes dessa etapa da pesquisa, elegeu-se o curso de Ciências Biológicas, dada sua proximidade maior com o tema da pesquisa, e de mais um curso de licenciatura, mas que estivesse distanciado das áreas afins, nesse caso, a Pedagogia. Importante frisar que ambos os grupos de participantes exibem grau mínimo de informação advindo da formação escolar básica e do contato com as publicaçôes midiáticas, veículos que afetam diretamente a conversação cotidiana das pessoas e, consequentemente, a formação das representaçôes sociais.

Em razão disso, optou-se por contatar alunos que estivessem cursando os primeiros anos dos cursos, sendo a amostra de 106 na Pedagogia e 73 na Biologia. Isso pelo fato do curso de Pedagogia registrar dois ingressos anuais de 45 estudantes; nesse caso, com o $1^{\circ}$ e o $2^{\circ}$ ano foi possível finalizar a coleta. Já o curso de Biologia caracteriza-se por um único ingresso anual, para 
apenas turno integral, com turmas de 30 estudantes; assim, optou-se por não ultrapassar o $5^{\circ}$ semestre para náo ultrapassar o terceiro ano de curso e obter o mesmo padrão na escolha dos participantes, atentando que tais diferenças no percurso universitário podem acarretar impactos nas representaçóes. Desse modo, foi possível atingir um total de 179 alunos. Em virtude do método de pesquisa adotado, a amostra foi composta por quase duas centenas de estudantes, quantitativo necessário para esse tipo de pesquisa para que haja estabilidade dos dados e também quantidade suficiente de material prestante a análises comparativas, a partir do software EVOC.

A tabela 1 apresenta algumas características do perfil dos estudantes que participaram da pesquisa, no que diz respeito à religiáo e ao curso dos participantes.

Tabela 1 - Religião dos estudantes dos cursos de Pedagogia e Ciências Biológicas n=179

\begin{tabular}{l|c|c|c|c|c|c}
\hline \multirow{2}{*}{ Religião Curso } & \multicolumn{2}{|c|}{ Pedagogia } & \multicolumn{2}{c|}{ Biologia } & \multicolumn{2}{c}{ Total } \\
\cline { 2 - 7 } & $\mathrm{N}$ & $\%$ & $\mathrm{n}$ & $\%$ & $\mathrm{~N}$ & $\%$ \\
\hline Católico & 39 & 36,79 & 23 & 31,51 & 62 & 34,64 \\
\hline Evangélico & 35 & 33,02 & 9 & 12,33 & 44 & 24,58 \\
\hline Ateu & 2 & 1,89 & 10 & 13,70 & 12 & 6,70 \\
\hline Espírita & 7 & 6,60 & 2 & 2,74 & 9 & 5,03 \\
\hline Budista & 0 & 0,00 & 1 & 1,37 & 1 & 0,56 \\
\hline $\begin{array}{l}\text { Tem fé em Deus, mas não } \\
\text { religião }\end{array}$ & 15 & 14,15 & 15 & 20,55 & 30 & 16,76 \\
\hline Outro & 8 & 7,55 & 13 & 17,81 & 21 & 11,73 \\
\hline Total & 106 & 100,00 & 73 & 100,00 & 179 & 100,00 \\
\hline
\end{tabular}

Fonte: Tabela elaborada pela pesquisadora.

Nota-se que o cristianismo está bastante presente nas crenças dos estudantes, pois a soma de participantes católicos e evangélicos totaliza 59,22\%, índice ainda maior se considerarmos somente os estudantes de Pedagogia, alcançando $69,81 \%$ desse grupo. Isso nos fala de crenças e valores que certamente permearão a construçáo das representaçóes dessas pessoas. Interessante demarcar que, 
em pesquisa realizada pelo Data Folha, em 2010, com 4.158 pessoas, em 168 municípios brasileiros, com idade superior a 16 anos, concluiu-se que 59\% dos investigados disseram acreditar que os seres humanos se desenvolveram ao longo de milhóes de anos, a partir de formas menos evoluídas, mas com Deus guiando esse processo de evoluçáa.

\section{Procedimentos e técnicas}

A coleta foi realizada mediante aplicação coletiva, em média 30 minutos para cada turma. Os alunos tomaram conhecimento do Termo de Conhecimento Livre e Esclarecido, que, apresentado oralmente pela pesquisadora, foi depois entregue para que dessem ciência do documento.

Utilizou-se da técnica de associação de palavras, com a apresentação de termos, comumente a designação do próprio objeto da representação, que vai induzir evocaçóes de outras palavras ou expressóes. Para processamento desses dados, valeu-se do recurso informático software Ensemble de programmes permettant l'analyse des evocations (EVOC), versão 2000, criado por Pierre Vergès, apresentado por Sá (2002).

O processamento dos dados enseja um quadrante que retrata a estrutura dos elementos da representação social. Segundo as ponderações de Sá (2002), os vocábulos de maior relevância ao grupo, tendo como referência a ordem de importância e frequência, ficam organizados da seguinte forma (Quadro 1):

Quadro 1 - Organização dos elementos estruturais das representações sociais

\begin{tabular}{|l|l|}
\hline \multicolumn{1}{|c|}{$1^{\circ}$ Quadrante } & \multicolumn{1}{|c|}{$2^{\circ}$ Quadrante } \\
$\begin{array}{l}\text { Atributos com alta frequência (f) } \\
\text { e elevada ordem de importância (OMI) }\end{array}$ & $\begin{array}{l}\text { PRIMEIRA PERIFERIA } \\
\text { Atributos com alta frequência (f) } \\
\text { e baixa ordem de importância (OMI) }\end{array}$ \\
\hline $\begin{array}{l}3^{\circ} \text { Quadrante } \\
\begin{array}{l}\text { ELEMENTOS DE CONTRASTE } \\
\text { etributos com baixa frequência (f) }\end{array}\end{array}$ & $\begin{array}{l}\text { SEGUNDA PERIFERIA } \\
\text { elevada ordem de importância (OMI) } \\
\text { Atributos com baixa frequência (f) } \\
\text { e baixa ordem de importância (OMI) }\end{array}$ \\
\hline
\end{tabular}

Fonte: (com base em: Sá, 2002)

O primeiro quadrante agrupa os atributos mais frequentes e elevada ordem média de importância (OMI). São os elementos denominados Núcleo Central (NC) das representaçóes, que se caracterizam pela estabilidade e resistência às mudanças (SÁ, 2002). 
Já o segundo quadrante, abriga os atributos mais frequentes, entretanto, pouco importantes na avaliaçáo dos participantes, classificados como Primeira Periferia. Já na Segunda Periferia, o quarto quadrante, estão os atributos mais instáveis das representaçóes, uma vez que possuem baixa frequência e também foram menos importantes para os participantes (SÁ, 2002).

O terceiro quadrante, denominado Elementos de Contraste, apresenta palavras de baixa frequência, portanto, menos recorrentes no discurso dos participantes, que, no entanto, foram muito importantes para eles. Pela relevância na fala das pessoas, por sua elevada ordem de importância, esse grupamento pode relevar o pensamento de algum subgrupo que está se posicionando que confronta o Núcleo Central da representação (SÁ, 2002).

Ao utilizar a técnica de evocação de palavras, o termo indutor selecionado foi Teoria da Evolução, ponderando que se solicitava a emissão de cinco palavras aleatórias ou expressóes que, posteriormente, foram classificadas pela ordem de importância, de acordo com o critério de escolha do estudante participante da pesquisa.

Com o intuito de auxiliar na identificação das atitudes em relação ao objeto de representaçáo, solicitava-se aos participantes que indicassem o caráter positivo, negativo ou neutro, conforme o haviam evocado. Por último, para complementar a compreensão do significado dos termos evocados, solicitava-se que se justificasse, em breves palavras, a expressão tida como a mais importante.

\section{Resultados e discussão: representações sociais da Teoria da Evolução}

Para a composição dos quadrantes que indicam a estrutura das representaçóes sociais, realizou-se recorte no corpus, obtendo-se aproveitamento de $43,5 \%$ do total das evocações. O Quadro 2 apresenta a estrutura temática das representaçóes sociais sobre a Teoria da Evoluçáo, de acordo com as falas do universo de estudantes de licenciatura. 
Quadro 2 - Estrutura temática da representação da Teoria da Evolução pelo conjunto de estudantes de licenciatura. $\mathrm{N}=179$. Cuiabá, 2012

\begin{tabular}{|c|c|c|c|c|c|c|c|}
\hline OMI & \multicolumn{3}{|l|}{$<3,00$} & \multicolumn{4}{|c|}{$\geq 3,00$} \\
\hline $\mathrm{f}$ & \multicolumn{3}{|l|}{ NÚCLEO CENTRAL } & \multicolumn{4}{|c|}{ PRIMEIRA PERIFERIA } \\
\hline \multirow{7}{*}{$\geq 30$} & Atributos & $\mathbf{f}$ & OMI & Atributos & & f & OMI \\
\hline & seleccão natural (+) & 53 & 2,151 & macacos & $(-)$ & 42 & 3,571 \\
\hline & Darwin $\quad(+)$ & 44 & 2,227 & evolução & $(+)$ & 30 & 3,100 \\
\hline & adaptação & 39 & 2,256 & & & & \\
\hline & homem & 37 & 2,703 & & & & \\
\hline & mutação & 30 & 2,800 & & & & \\
\hline & \multicolumn{3}{|l|}{ ELEMENTOS DE CONTRASTE } & \multicolumn{4}{|c|}{ SEGUNDA PERIFERIA } \\
\hline \multirow{6}{*}{$<30$} & Atributos & f & OMI & Atributos & & f & OMI \\
\hline & desenvolvimento/crescimento $(+)$ & 25 & 2,720 & espécies & $(+)$ & 15 & 3,600 \\
\hline & ciência & 23 & 2,435 & & & & \\
\hline & pesquisa & 18 & 2,667 & & & & \\
\hline & conhecimento & 16 & 2,625 & & & & \\
\hline & deus & 15 & 1,800 & & & & \\
\hline
\end{tabular}

Fonte: Quadro elaborado pela pesquisadora.

Conforme se observa, existem agrupamentos de palavras com relação de sentido. Estabelecem aquilo que em representaçóes se compreende como conexidade entre os termos. O primeiro foi denominado Conceitos relacionados com a Teoria da Evolução, privilegiando a temática seleção natural, adaptação e mutação, no Núcleo Central; evolução, na Primeira Periferia; e espécies na Segunda Periferia. Diante dessas expressóes, é possível notar que os conceitos básicos da teoria foram evocados pelos participantes, com alto grau de importância, tendo em vista que abrangem grande parte no Núcleo Central, quadrante que abriga as palavras de alta frequência e elevada ordem de importância. Além disso, apresentaram conexão com elementos da primeira e segunda periferia. Isso sinaliza que essa teoria, estabelecida há 150 anos, tem seus conceitos centrais fazendo parte da centralidade do discurso desses estudantes.

Interessante destacar que o posicionamento dos participantes da pesquisa, ao avaliarem esses atributos, foi, em sua maioria, positivo, conforme está demarcado à frente dos atributos com sinal (+), para avaliaçóes positivas, e sinal (-) para avaliaçóes negativas, assinalando que esse grupo revelou atitude favorável diante do tema. Esse método foi adotado por entender que as atitudes são consideradas predisposição à ação, como bem expressa Moscovici (2003). 
É possível verificar como esses conceitos estão apropriados pelos participantes da pesquisa, ao tomar como exemplo o conceito seleçáo natural nas justificativas emitidas pelos estudantes:

\section{Seleçáo natural}

De acordo com a teoria, é por meio da seleção natural que ocorre a evolução das espécies. (participante 40, estudante de Pedagogia).

A seleção natural seria a base da evolução que seria, pois os mais aptos à sobrevivência e reprodução seriam selecionados e os outros morreriam de acordo com o meio em que vivem. (participante 114, estudante de Ciências Biológicas).

Somados ao conceito de seleção natural, os termos adaptação e mutação também comparecem no Núcleo Central, por sua alta frequência e valorizada ordem de importância. São justificados com as seguintes observaçóes:

\section{Adaptação}

Adaptação foi a consequência pela qual o planeta e o homem passaram pela ação sofrida, seja ela de que natureza for, transformando o meio ambiente em todos os sentidos. (participante 106, estudante de Pedagogia).

Adaptação: na Teoria da Evolução, sem dúvida, "a adaptaçấo" é um fator muito importante, para evoluir é necessário se adaptar a novas condiçôes a que se está submetido em determinado momento. (participante 111, grifo da participantes, estudante de Ciências Biológicas).

\section{Mutação}

Mutação significa uma melhoria no desenvolvimento da espécie. (participante 1, estudante de Pedagogia).

Uma mutação genética é a base para a evolução, caso esta se torne hereditária numa determinada população. (participante 156, estudante de Ciências Biológicas).

Ainda que não seja o objetivo desta discussão realizar comparativos entre os dois grupos de estudantes, destaca-se a importância desse grupo de palavras para os estudantes de Biologia mediante análise dos relatórios do subprograma COMPLEX, que apresenta os atributos seleção natural, adaptação e mutação como específicos desse subgrupo, em comparação com a Pedagogia. Isso significa que foram expressóes características das falas dos estudantes de Biologia e que, apesar de constarem nas representaçóes da Pedagogia, esses termos náo são expressivos em seus discursos. 
Conforme mencionado, existe também outro atributo dessa categoria na Primeira Periferia, evolução, com as seguintes justificativas:

\begin{abstract}
Evolução
É mais importante porque está relacionado com o próprio nome da teoria e, portanto, é a primeira palavra que me veio à lembrança. (participante 32, estudante de Pedagogia).

A palavra evolução, pelo fato de ser a palavra que explica a teoria que Charles Darwin mostrou. Esta é a palavra que representa sua teoria como um todo. (participante 139, estudante de Ciências Biológicas).
\end{abstract}

O termo evolução, assim como a expressão macaco, constam com frequências que poderiam pertencer ao Núcleo Central (Quadro 2). Todavia, devido a sua ordem de importância, tais palavras comparecem somente na Primeira Periferia, pois não obtiveram elevada ordem de importância. Isso leva à análise da centralidade dos termos, tendo em vista que são termos que podem ser considerados centrais nas representaçóes sociais; entretanto, não houve um teste de centralidade para realizar tais afirmaçóes.

Ainda entre os Conceitos relacionados com a Teoria da Evolução consta na segunda periferia a palavra espécies com baixa frequência e baixa ordem de importância. Não houve nenhuma justificativa justamente porque foi classificada tardiamente e ninguém a escolheu como primeira alternativa, registrando-se que somente essa era a que recebia justificativa dos estudantes.

Como se pode perceber, os conceitos centrais da teoria evolucionista foram lembrados pelos estudantes participantes, tendo em vista que foram recorrentes no Núcleo Central das representaçóes e também no Sistema Periférico. Isso elucida uma representação social que apresenta os conceitos do universo reificado, não sem pontuar que algumas justificativas mostram um repertório linguístico com mais embasamento teórico. Já outras apresentam os conceitos de modo genérico, característica que pode sinalizar diferenças no discurso dos grupos pesquisados. Posto isso, verifica-se que tais conteúdos traduzem a estabilidade da representação social. São os elementos mais rígidos e resistentes à mudança, logo, são pouco sensíveis ao contexto imediato, conforme define Abric (2003).

O segundo bloco, com palavras que estabeleceram entre si redes de sentido, foi denominado Influências e Legados da Teoria da Evolução, alicerçado pelos atributos desenvolvimento/crescimento, ciência, pesquisa e conhecimentos, todos abrigados nos Elementos de Contraste. Entre as justificativas dos estudantes transitam: 


\section{Desenvolvimento/crescimento}

Desenvolvimento por acreditar que a evolução é um processo de desenvolvimento dos seres. (participante 8, estudante de Pedagogia).

$O$ desenvolvimento do ser humano aprimora. (participante 37, estudante de Pedagogia).

\section{Ciência}

Pois é através dela que buscamos compreender e adquirir conhecimento. (participante 64, estudante de Pedagogia). Através da ciência, que concretizou a Teoria da Evolução das espécies. (participante 108, estudante de Ciências Biológicas).

\section{Pesquisa}

A pesquisa gera conhecimento sobre o início da vida na terra e tenta explicar a evolução desta, trazendo junto conflitos, lendas e mitos. (participante 18, estudante de Pedagogia).

\section{Conbecimento}

Conhecimento é a base de tudo para se prosseguir numa pesquisa, ou para se envolver em qualquer área da ciência é necessário ter o conhecimento. (participante 120, estudante de Ciências Biológicas).

Interessante destacar a justificativa do participante 18 quando evoca a palavra pesquisa, pois apóe esse termo para dar explicação sobre a evolução, associando-o a conflitos, lendas e mitos. Não é outro o interesse desta investigação: analisar o conhecimento científico, com base no depoimento das pessoas, examinando o senso comum, as crenças, atitudes e opinióes sobre o tema.

Essa categoria concentra expressóes voltadas às descriçóes práticas, classificadas por Abric (2003) como elementos funcionais, aqueles que se referem às açôes, aos atributos que tratam da realização de uma prática. Por outras palavras, os elementos que determinam e organizam as condutas relativas à Teoria da Evolução. Pode-se ainda compreender que tais elementos sinalizam o contraste em relação aos conteúdos apresentados no Núcleo central, posto que são pouco mencionados, mas bem valorizados para um pequeno grupo.

Apresenta-se, ainda, no Núcleo Central, o nome do Propositor da Teoria, Charles Darwin. Eis as justificativas empregadas pelos estudantes: 


\section{Darwin \\ Darwin: considero a mais importante, porque foi o cientista que estudou a origem, desenvolvimento e evolução de uma teoria baseada na humanidade, reunindo diversos estudos e informaçôes essenciais. (participante 76, estudante de Pedagogia). \\ Pois foi Darwin quem iniciou o que hoje conhecemos por evolução, tendo a curiosidade e agrupando informaçōes que ele tinha ou que obteve através da viagem em torno do mundo. (participante 117, estudante de Ciências Biológicas).}

A denominação Darwin foi a segunda mais frequente em todo o corpus, com classificação de importância entre a primeira e a segunda palavra. Outros teóricos também foram lembrados, mas não o suficiente para comparecer quadrantes, entre eles Lamarck, com frequência sete, e Wallace, com apenas uma recorrência. Sendo assim, não há impacto no discurso dos estudantes da Biologia nem da Pedagogia para compor a análise das representaçóes dos estudantes. Isso reforça a tese de que a Teoria evolucionista está fortemente atrelada à imagem de Darwin.

Completando a análise do Núcleo Central, denota-se, igualmente, a palavra homem, compreendida como Objeto de Investigação da Teoria da Evolução, cujas justificativas foram:

\section{Homem}

$\mathrm{Na}$ Teoria da Evolução, o homem é o principal e mais importante por ser o elemento a ser estudado cientificamente. (participante 57, estudante de Pedagogia).

As palavras homem e Darwin também foram avaliadas positivamente, o que expressa um posicionamento favorável desse grupo, confirmando a atitude positiva dos participantes da pesquisa em relaçáo à proposta de evolução do homem e a seu principal propositor.

Também com elevada frequência, mas numa ordem de importância tardia, evocaram o termo macacos, que representa Distorção em relação à Teoria da Evolução. Os excertos que justificam essa palavra, ei-los:

\footnotetext{
Macacos

Acredito que, quando se fala da Teoria da Evolução, sempre se remete ao macaco com a origem do homem, embora eu näo concorde com esta teoria. (participante 48, estudante de Pedagogia).

Conforme estudos, evoluimos do macaco. (participante 66, estudante de Pedagogia).
} 
Pelo elevado índice de frequência, constata-se que esse assunto seja polêmico, fundamentado na crença distorcida em relação à proposição inicial de Charles Darwin sobre a existência de um ancestral comum, conforme exposto no esquema da árvore da vida. Isso demonstra a possibilidade da representação sofrer distorção, suplementação ou subtração, como acentua Jodelet (2001). Nesse caso, apresenta-se como distorção, visto que os atributos do objeto representados são acentuados, sucedendo mecanismos de inversão das características entremostradas pelo objeto.

No comparativo do subprograma COMPLEX, as únicas palavras estatisticamente representativas para o grupo da Pedagogia, em relação à Biologia, foram homem e macacos, sendo essa última exclusiva da Pedagogia, o que patenteia diferença nos discursos, revelando representaçôes sociais construídas com maior distanciamento do universo reificado.

A presença do atributo Deus reitera que ainda estamos diante de um tema que enseja polêmica. Por ser Elemento de Contraste, denota baixa frequência, mas é importante para esse pequeno subgrupo que evocou, sendo o termo de menor Ordem Média de Importância no quadrante (OMI - 1,800). Conforme apresentado no perfil dos estudantes, as religióes cristãs foram bastante incidentes entre eles (59,22\%), entretanto, isso não se apresentou como elemento hegemônico nas representaçôes, tendo em vista a baixa frequência desse elemento na estrutura das representaçóes. Todavia, as pessoas que evocaram a palavra Deus demarcam a relevância de sua crença, dada a importância atribuída ao termo, ficando entre a primeira e segunda colocação, em meio às cinco palavras solicitadas. Para tal atributo, as justificativas foram as seguintes:

\begin{abstract}
Deus
Deus, como acredito no criacionismo, essa palavra é mais importante porque segue caminhos certos, e não são duvidosos. (participante 67, estudante de Pedagogia).

Deus: eu considerei importante esta palavra, pois Deus está entre o criacionismo e o evolucionismo e uma coisa puxa a outra, todos têm um grau de importância. (participante 149, estudante de Ciências Biológicas).
\end{abstract}

Importante destacar que, por se tratar de expressão com baixa frequência, ao separar os elementos estruturais de cada grupo estudado, não foi possível detectar a presença desse atributo na composição de suas representações. Isso se reforça na análise dos relatórios do COMPLEX, pois não comparece como palavra específica em nenhum dos grupos de estudantes.

Diante de matéria com posiçóes contraditórias, percebe-se significativa característica das representaçôes sociais, que é abrigar concepçôes diferentes 
no Sistema Periférico. Esse, conforme conceitua Abric (2003), representa a parte mais acessível e viva da representação, correspondendo a seus dados mais concretos, cuja funçáo é sustentar e proteger o núcleo por sua flexibilidade com as diferenças. Portanto, não se trata de discurso consensual na fala do grupo geral, mas expóe que, entre os estudantes, há possibilidade de convívio com convicções diferentes.

\section{Considerações finais}

A configuração da presente pesquisa trouxe o olhar da psicologia social para um tema amplamente privilegiado pela história da ciência, bastante explorado nos domínios político, religioso, econômico e cultural. Tratou-se, portanto, de examinar a Teoria da Evolução, como objetos de representação, em recorte populacional específico da sociedade contemporânea brasileira que presencia a passagem dos 150 anos dessa teoria.

O estudo apontou, ainda, forte ligação entre a Teoria da Evolução e a figura de Darwin, pois, a propósito, existem as mais diferentes teorizaçóes acerca da evolução, até mesmo a circunscrição dessa proposta por outro autor, como é o caso de Wallace. Nesse sentido, confirma-se que a imagem de Darwin está imbricada no conceito dessa teoria, ocorrendo aquilo que, em representaçóes sociais, é chamado de objetivação pela personificação.

O conjunto de estudantes universitários caracterizou, em suas representaçóes sociais, que as crenças religiosas tiveram pouca evidência no que alude à Teoria da Evolução. Todavia, merece ser pontuado que um subgrupo manifestou sua fé em Deus como condutor do processo da criaçáo do mundo, o que náo chegou a compor a centralidade da representação, mas para esse pequeno grupo isso parece ser verdade inegociável.

De outra parte, não raras vezes, se vê representada a imagem do macaco em processo evolutivo, passando por hominídeos, até chegar à figura do homem ereto, associada à Teoria da Evolução darwinista. Essa crença foi compreendida neste estudo como distorçáo da teoria. Tal ideia, imbricada na estrutura das representaçóes sociais, sugere que, mesmo diante da hegemonia das atitudes, valores e crenças, sinalizando os conceitos centrais da teoria, patenteia que, para a minoria de estudantes, trata-se ainda de tema controverso.

Ainda que não traduza consensualidade, deparar-se com distorçóes e crenças inegociáveis enfatiza a necessidade do potencial formativo da academia para ensejar a construção de novas representaçóes; com isso, futuras geraçóes podem ter acesso à formação de qualidade. 
Conclui-se que, com o passar de 150 anos, a Teoria da Evolução, de Darwin, está presente no conhecimento popular, atravessada por aceitaçóes, dúvidas, questōes e distorçóes, e, em meio a essa ambivalência, vem rompendo as barreiras do universo científico para circular no senso comum. Mais que isso: faz parte do cotidiano das pessoas, do repertório linguístico em suas conversaçóes habituais, e, consequentemente, servirá de guia para a prática profissional desses educadores em formação.

\section{Referências}

ABRIC, Jean-Claude. A abordagem estrutural das representaçóes sociais. Desenvolvimentos recentes. In: CAMPOS, P. H. F.; LOUREIRO, M. C. S. (Org.). Representaçóes sociais e práticas educativas. Goiânia: Ed. da UCG, 2003. p. 37-57.

BROWNE, Janet. A origem das espécies de Darwin: uma biografia. Tradução de Maria Luiza X. de A. Borges. Rio de Janeiro: Jorge Zahar Editor, 2007.

CLÉMENCE, Alain; GREEN, Eva G. T.; COURVOISIER, Nelly. Comunicação e ancoragem: difusão e transformação das representaçóes sociais. Tradução José Geraldo de Oliveira Almeida. In: ALMEIDA, Angela Maria de Oliveira; SANTOS, Maria de Fátima Souza; TRINDADE, Zeidi Araujo. Teoria da representaçóes sociais: 50 anos. Brasília: Technnopolitik, 2011.

DARWIN, Charles. Autobiografia 1809-1882. Tradução de Vera Ribeiro. Rio de Janeiro, 2000.

DATAFOLHA. Instituto de Pesquisa. 59\% acreditam na evoluçáo entre as espécies, sob o comando de Deus. Disponível em: http://datafolha.folha.uol. com.br/opiniaopublica/2010/04/1223573-59-acreditam-na-evolucao-entre-asespecies-sob-o-comando-de-deus.shtml. Acesso em: 05 mar. 2012.

DI MARE, Rocco Alfredo. Desenvolvimento da Teoria da Evolução como uma teoria científica. In: A concepçáo da teoria evolutiva desde os gregos: ideias, controvérsias e filosofias. Porto Alegre: EDIPUCRS, 2002. p. 95-117.

DORVILLÉ, Luís Fernando Marques. Religiáo, escola e ciência: conflitos e tensóes nas visóes de mundo de alunos de uma licenciatura em ciências biológicas. Tese (Doutorado) - Universidade Federal Fluminense, Faculdade de Educação, 2010.

JODELET, D. Representações sociais: um domínio em expansão. In: (Org.). 
As representaçóes sociais. Tradução de Lílian Ulup. Rio de Janeiro: EdUERJ, 2001. p. 17-44.

MOSCOVICI, Serge. A representaçáo social da psicanálise. Rio de Janeiro: Zahar, 1978.

MOSCOVICI, S. Representaçóes sociais: investigações em psicologia social. Tradução de Pedrinho A. Guareschi. Petrópolis: Vozes, 2003.

PAGAN, Acácio Alexandre. Ser (animal) humano: evolucionismo e criacionismo nas concepçôes de alguns graduandos em ciências biológicas. Tese (Doutorado) Universidade de São Paulo, 2010.

SÁ, Celso Pereira. Núcleo central das representaçóes sociais. Petrópolis: Vozes, 2002. 